\title{
Microstructural investigations of bulk metallic glass using small-angle neutron scattering techniques
}

\author{
Vasyl Ryukhtin $^{\text {a, }}$, Sergiy Bakai ${ }^{\mathrm{b}}$, Tae-Gyu Shin ${ }^{\mathrm{c}}$, Baek S. Seong ${ }^{\mathrm{c}}$, Vitaliy Pipich ${ }^{\mathrm{d}}$, \\ Artem Feoktystov ${ }^{\mathrm{d}}$, Nelia Wanderka ${ }^{\mathrm{e}}$, Oleksandr Bakai ${ }^{\mathrm{b}}$ \\ ${ }^{a}$ Nuclear Physics Institute, v.v.i., ASCR, 25068 Rež, Czech Republic \\ ${ }^{\mathrm{b}}$ Institute of Physics and Technology of the UAS, Kharkiv, 1 Akademichna, 61108, Ukraine \\ ${ }^{\mathrm{c}}$ KAERI, 1045 Daedok-daero, Yuseong-gu, Daejeon, Republic of Korea \\ d Jülich Centre for Neutron Science (JCNS) at Heinz Maier-Leibnitz Zentrum (MLZ), Lichtenbergstr. 1, 85748, Garching, Germany \\ ${ }^{\mathrm{e}}$ Helmholtz-Zentrum Berlin für Materialien und Energie, Hahn-Meitner-Platz 1, 14109 Berlin, Germany
}

A R T I C L E I N F O

\section{Keywords:}

bulk metal glass

Vitreloy 4

Small-angle neutron scattering

\begin{abstract}
A B S T R A C T
Bulk metallic glasses (BMG) are very attractive materials exhibiting high specific strength, decent corrosion resistance and other benefiting features due to their amorphous microstructure. However, the mechanisms of mechanical properties as an issue of structure-properties relation in BMGs are not understood as well as those in polycrystalline materials. For example, the driving force for fatigue in crystalline materials is connected to grain boundary slip and the formation of dislocations i.e. to those structural elements whose existence in BMGs is still debatable. In order to find a link between the mechanical properties and the microstructure in BMG, researchers investigate structural heterogeneities i.e. clusters. The size order of the clusters and intercluster boundaries are within the resolution of small-angle neutron scattering (SANS) techniques. Here we present the results of SANS and very-small-angle neutron scattering (VSANS) studies of $\mathrm{Zr}_{46.75} \mathrm{Ti}_{8.25} \mathrm{Cu}_{7.5} \mathrm{Ni}_{10} \mathrm{Be}_{27.5}$ bulk metallic glass after deformation with and without ultrasonic vibrations. VSANS measurements revealed the creation and growth of large micropores induced by ultrasonic vibration.
\end{abstract}

\section{Introduction}

The $\mathrm{Zr}_{46.75} \mathrm{Ti}_{8.25} \mathrm{Cu}_{7.5} \mathrm{Ni}_{10} \mathrm{Be}_{27.5}$ alloy, commonly referred to as Vit. 4 invented first by Johnson et al. [1,2], is one of the best bulk metallic glass (BMG) formers with a distinct stability of the supercooled melt above the glass transition temperature at $603 \mathrm{~K}$ [3-5]. Vit. 4 is one of the first BMG materials which has found its commercial application: it is used for the fabrication of golf club heads. A maximum of energy is transferring to the kinetic energy of the ball in a moment of collision with the golf head due to the practical absence of plastic deformation in this BMG material.

The first calorimetric crystallization temperature of this BMG is at $730 \mathrm{~K}$. An exceptionally extended region of the supercooled liquid phase indicates a high resistance against crystallization. Many studies have investigated this pronounced stability. It has been found that the crystallization depends on the preceding thermal treatment. The crystallization at different heat treatments follows different pathways. In the end different phases are crystallized. For instance, phase separation of amorphous $\mathrm{Zr}_{41} \mathrm{Ti}_{14} \mathrm{Ni}_{10} \mathrm{Cu}_{12.5} \mathrm{Be}_{22.5}$ (Vit.1) glass in to two supercooled liquids has been reported after heat treatment at $643 \mathrm{~K}$ for $15 \mathrm{~h}$ [6]. Field ion microscopy with atom probe (FIM/AP) revealed compositional fluctuations during the phase separation and showed anti-correlated fluctuations of $\mathrm{Ti}$ and $\mathrm{Be}$. It was also found that $\mathrm{Zr}, \mathrm{Cu}$ and $\mathrm{Ni}$ do not participate significantly in the decomposition [6]. Phase separation of the same glass at $623 \mathrm{~K}$ and $643 \mathrm{~K}$ was confirmed by in-situ SANS measurements [7]. Droplet-like nanosized amorphous particles develop in the amorphous matrix [7]. In contrast, the Vit. 4 bulk glass shows the formation of quasicrystalline phase during isothermal annealing at the same temperature of $643 \mathrm{~K}$ for $6 \mathrm{~h}$ [8]. A detailed study of the crystallization of the Vit. 4 shows that during a heat treatment below the glass transition at $573 \mathrm{~K}$, even after annealing periods of up to 128 days no crystalline or quasi-crystalline phases have been detected [9]. However, the subsequent heating of the Vit. 4 glass favors the formation of a quasi-crystalline phase which is very much depleted in Be [9,10]. Little is known how the bulk amorphous alloys behave under plastic deformation. Deformation-induced crystallization of Al-rich amorphous alloys

\footnotetext{
* Corresponding author.

E-mail address: ryukhtin@ujf.cas.cz (V. Ryukhtin).
} 
has been observed after cold rolling [11], nanoindentation [12] and high pressure torsion (HPT) $[13,14]$.

Methods of experimental and theoretical investigations of BMGs are quite different from those of polycrystalline metals due to the amorphous ("shape-less") microstructure. There are only few theoretical approaches describing BMGs. For example, for describing the deformation one can consider the BMG microstructure as density fluctuations regions - clusters surrounded by a softer phase.

SANS is quite a useful non-destructive method for studying the microstructure in a nano- and mesoscopic size range. It is not sensitive to the surface, usually does not require any sample preparation and describes the bulk of studied material with excellent statistics. However, data interpretation might be distorted by the simplification of a fitting model.

SANS instruments were successfully used for investigation of the ZnTi-Cu-Ni-Be BMG microstructure, e.g. spinodal decomposition was observed during in-situ measurements at annealing temperatures close to the glass transition temperature $\mathrm{T}_{g}[15-17]$.

In the present work we applied SANS for studying BMG samples deformed in plastic mode in order to gain information about the microstructural changes. The samples were investigated after mechanical deformation with and without ultrasonic vibrations (USVs).

\section{Experimental}

The $\mathrm{Zr}_{46.8} \mathrm{Ti}_{8.2} \mathrm{Cu}_{7.5} \mathrm{Ni}_{10} \mathrm{Be}_{27.5}$ alloy was produced by alloying the constituent elements of $99.99 \%$ purity by induction melting in a levitation device under purified Ar atmosphere and quenching by the contact with water cooled copper surface. Glassy ingots of about $15 \mathrm{~mm}$ thickness and $20 \mathrm{~mm}$ diameter were obtained.

For deformation experiments the samples of $3 \mathrm{~mm}$ in diameter and $4 \mathrm{~mm}$ length were cut from the ingots. The deformation experiments are performed in air under compression stress with and without USV. The samples \#01 and \#03 were monotonically loaded at constant strain rates

Table 1

Parameters of the sample treatments.

\begin{tabular}{|c|c|c|c|c|c|}
\hline Sample & $\begin{array}{l}\text { Amplitude } \\
\text { of USV }\end{array}$ & Temp., K & $\dot{\varepsilon}, \mathrm{s}^{-1}$ & Time, s & Loading mode \\
\hline$\# 01$ & - & 573 & $7.5 \cdot 10^{-4}$ & 6000 & $\begin{array}{l}\text { constant length, the } \\
\text { stress recorded }\end{array}$ \\
\hline \#03 & $7 \mu \mathrm{m}$ & 568 & $2.5 \cdot 10^{-4}$ & 6000 & $\begin{array}{l}\text { constant length, the } \\
\text { stress recorded }\end{array}$ \\
\hline \#07 & $7 \mu \mathrm{m}$ & 548 & - & 5600 & $\begin{array}{l}\text { constant loading at } \\
850 \mathrm{~kg}(1061 \mathrm{MPa})\end{array}$ \\
\hline \#08 & - & 548 & - & 6650 & $\begin{array}{l}\text { constant loading at } \\
850 \mathrm{~kg}(1061 \mathrm{MPa})\end{array}$ \\
\hline
\end{tabular}

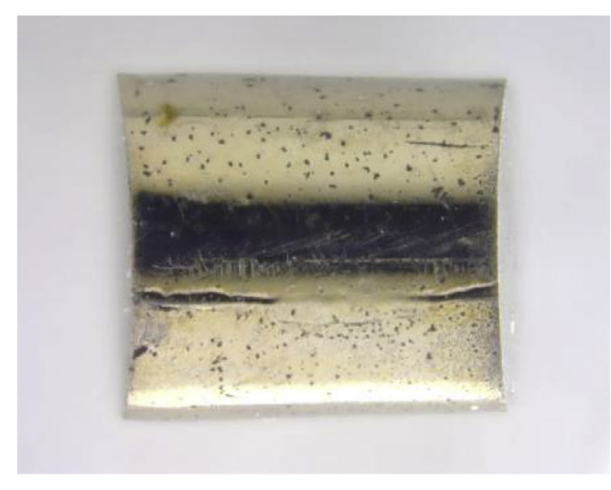

a) specimen $\# 07$ of $\sim 10^{-4} \mathrm{~s}^{-1}$ at a temperature close to the $\mathrm{T}_{\mathrm{g}}$. The samples \#07 and \#08 were deformed at constant loading (creep deformation) with $\mathrm{F}=750 \mathrm{~kg}$ (1061 MPa). The specimens \#03 and \#07 were deformed with ultrasound vibration (USV) of $20 \mathrm{kHz}$ with an amplitude of about $7 \mu \mathrm{m}$ (see Table 1).

The difference in shape between the samples treated with and without USV due to different fixing of the sides can be observed in Fig. 1. Both edge surfaces of the specimen \#08 were fixed because the sample was submitted to a large surface friction. As a result, its shape after deformation is barrel-like. One edge surface of the specimen \#07 was fixed while another one was free for sliding during USV impact. Therefore it has a conical shape.

The small-angle neutron scattering (SANS) experiments were carried out at two different instruments: 1) at $18 \mathrm{~m}$ SANS at HANARO (KAERI, Daejeon, Korea) and 2) KWS-1 SANS operated by the Julich Centre for Neutron Science (JCNS) at the research reactor FRM II of the Heinz Maier-Leibnitz Zentrum in Garching, Germany [18]. Deformation axis of the sample was aligned parallel to the incident neutron beam.

Very small-angle neutron scattering (VSANS) measurements of the BMG specimens were conducted at KWS-3 instrument (JNSC, Garching, Germany) [20].

\section{Results and discussion}

\subsection{Pin-hole SANS measurements}

In Fig. 2 the scattering cross-section curves obtained from the BMG samples are plotted as a function of $Q$ in double-logarithmic scales. The curves are characterized by different stages: after deformation with (samples \#03 and \#07) and without USVs (samples \#01 and \#08). The scattering functions at low momentum transfer Q (Fig. 2) follow powerlow dependences with non-integer exponent values close to -3 (Table 1 ). This may be evidence of fractal structure of density fluctuations in the measured size range [19].

The scattering curves in Fig. 2 of the samples (\#07, \#08) indicate the presence of the phase separation. The calculation shows the nanoscaled inhomogeneity's with radii $10-25 \mathrm{~nm}$.

The values of the fitted maxima of log-normal distribution of spheres radii are summarized in Table 2.

\subsection{VSANS measurements}

The same samples of $\mathrm{Zr}_{46.8} \mathrm{Ti}_{8.2} \mathrm{Cu}_{7.5} \mathrm{Ni}_{10} \mathrm{Be}_{27.5}$ alloy were also measured by VSANS. The scattering curves of investigated samples ( $\# 01$, \#03, \#07 and \#08) are shown in Fig. 3.

VSANS scattering intensities $S(Q)$ from the sample (\#01) and the sample deformed without high-frequency cycling stress \#08 are

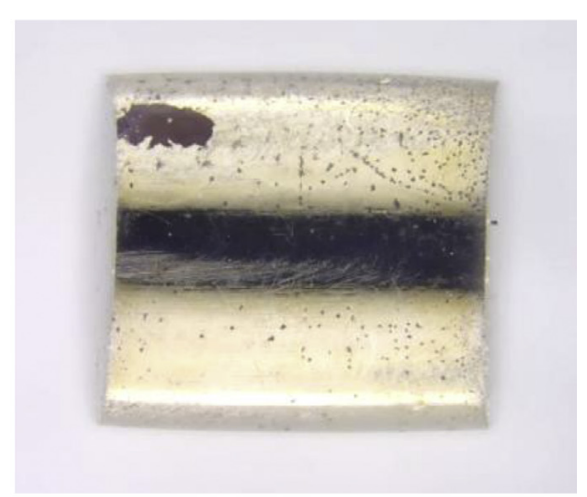

b) specimen \#08

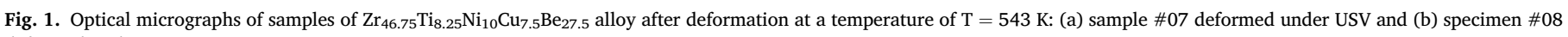
deformed without USV. 


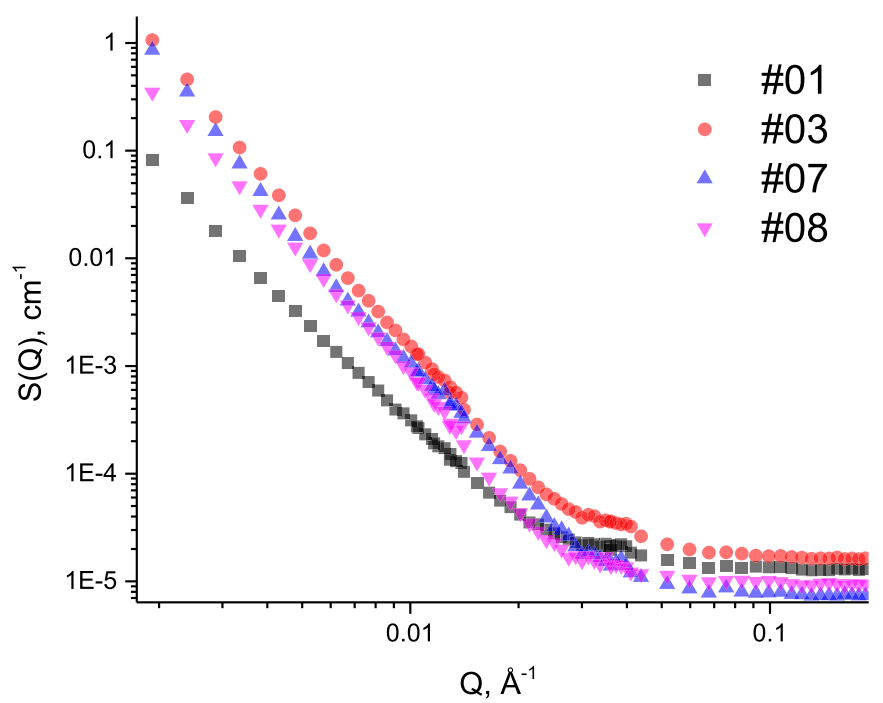

Fig. 2. Neutron scattering curves of the $\mathrm{Zr}_{46.75} \mathrm{Ti}_{8.25} \mathrm{Ni}_{10} \mathrm{Cu}_{7.5} \mathrm{Be}_{27.5}$ alloys after deformation with (samples \#03 and \#07) and without USVs (samples \#01 and \#08).

Table 2

Fitted parameters of pin-hole SANS data.

\begin{tabular}{llll}
\hline Sample & Exponent $\mathrm{D}$ & $\mathrm{R}_{\max }, \mathrm{nm}$ & $\sigma$ \\
\hline$\# 01$ & 2.92 & - & - \\
$\# 03$ & 3.01 & - & - \\
$\# 07$ & 3.04 & 9.4 & 0.38 \\
$\# 08$ & 2.97 & 24.3 & 0.1 \\
\hline
\end{tabular}

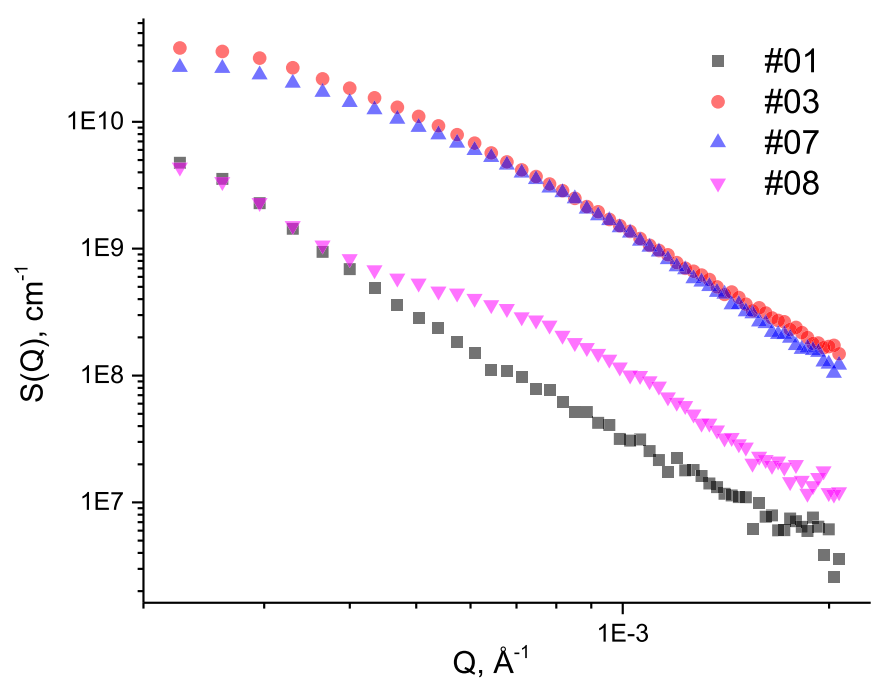

Fig. 3. Neutron scattering curves of the $\mathrm{Zr}_{46.75} \mathrm{Ti}_{8.25} \mathrm{Ni}_{10} \mathrm{Cu}_{7.5} \mathrm{Be}_{27.5}$ alloy after deformation with USV (samples \#03 and \#07) and without USV (samples \#01 and \#08) as measured by VSANS at KWS-3.

sufficiently lower than from the samples $(\# 03, \# 07)$ which were mechanically tested with USV. Most likely this difference is due the presence of large (about few $\mu \mathrm{m}$ ) cracks in these samples. Such cracks were described in a similar material $\left(\left(\mathrm{Zr}_{55} \mathrm{Al}_{10} \mathrm{Ni}_{5} \mathrm{Cu}_{30}\right)_{99} \mathrm{Y}_{1}\right)$ deformed with high-frequency $(20 \mathrm{kHz}) \mathrm{USV}$, as the coalescence of nano-crackes initiated from a slip at intercluster boundaries [21]. In addition, the sample \#08 has scattering evidence in the $Q$ region of about $5 \cdot 10^{-4} \div 8 \cdot 10^{-4} \AA^{-1}$ indicating smaller heterogeneities.

The SASfit software [22] was used for fitting the data using a log-normal distributions of simple spheres. The example of the data fitting for sample \#08 is demonstrated in Fig. 4.

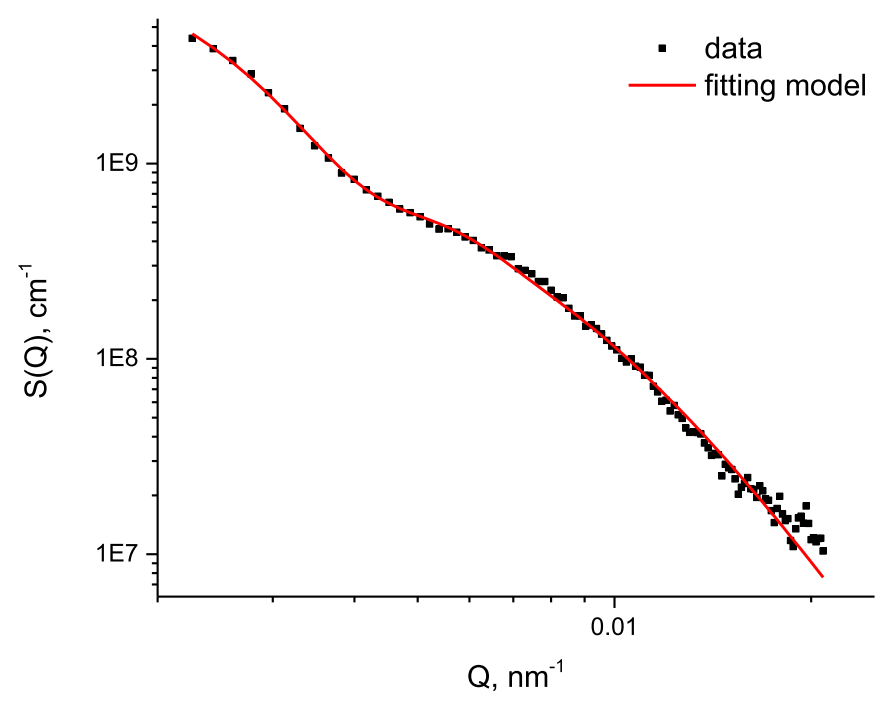

Fig. 4. Experimental VSANS data of sample \#08 (squares) with a fitted model of the lognormal distribution of spherical particles (red line).

Table 3

Fitted parameters of the VSANS data

\begin{tabular}{lll}
\hline Sample & $\mathrm{R}_{\max }, \mathrm{nm}$ & $\sigma$ \\
\hline$\# 07$ & 94 & 0.38 \\
$\# 08$ & 103.9 & 0.49 \\
\hline
\end{tabular}

The maximum values of the obtained size distributions and width parameters are summarized in Table 3.

VSANS scattering of two samples (\#07 and \#08) shows the presence of about $100 \mathrm{~nm}$ sized inhomogeneity's (see Table 3). Usually, the SANS signal is stronger in case of scattering from pores or cracks than that from precipitates or density fluctuations due to a higher scattering contrast. This point let us suggest that the strong signal for samples treated using USV comes from the coalesced cracks. The scattering effect from smaller inhomogenities is well observable for the sample \#07, but not for the samples \#03, although tales in the scattering functions from the microcracks sufficiently shadow in smaller $\mathrm{Q}$ region (around $10^{-3} \AA^{-1}$ ). These inhomogenities are supposed to be similar to those described earlier in Refs. [15-17] as a spinodal decomposition. However, in our case, the inhomogenities were induced by the plastic deformation not by the annealing. More investigations with complementary methods are necessary to find out the nature of the microstructure.

\section{Summary}

Pin-hole SANS and focused VSANS techniques were applied for the characterization of structural inhomogenities in Vit. 4 BMG. The observed increasing of VSANS intensity in the samples deformed with USV are proposed to originate from the merged cracks developed from intercluster boundaries. Since the structural changes are similar in quasistatic (sample \#03) and at constant loading (sample \#08) we conclude that the time of the USV treatment plays the decisive role in the structure rearrangements. The smaller submicrometers inhomogenities observed in the deformed BMG samples are subjected to a thermally activated phase separation at deformation and obviously not depended on the USV treatment. Pin-hole SANS curves of the specimens have a fractal region with exponent close to -3 from cluster self-similar short-range order.

\section{Acknowledgements}

This work was supported by the Czech Science Foundation under the project No. 14-36566G. The SANS results are based upon experiments 
performed at the KWS-1 and KWS-3 instruments (Garching, Germany) operated by JCNS at MLZ and $18 \mathrm{~m}$ SANS instrument at HANARO (KAERI, Daejeon, Korea). Many thanks to the scientific and technical workers who contributed to these SANS experiments.

\section{References}

[1] W.L. Johnson, Mater. Sci. Forum 225-227 (1996) 35-50.

[2] W.L. Johnson, MRS Bull. 24 (1999) 2-56.

[3] T. Waniuk, J. Schroers, W.L. Johnson, Appl. Phys. Lett. 78 (9) (2001) 1213-1215.

[4] T. Waniuk, J. Schroers, W.L. Johnson, Phys. Rev. B 15 (8) (2003) 1729-1734.

[5] Th Zumkly, V. Naundorf, M.-P. Macht, G. Frohberg, Scripta Mater. 45 (4) (2001) 471-477.

[6] M.-P. Macht, N. Wanderka, A. Wiedenmann, H. Wollenberger, Q. Wei, H. Fecht, S.G. Klose, Mater. Sci. Forum 225-227 (1996) 65-70.

[7] A. Wiedenmann, J.-M. Liu, Solid State Commun. 100 (1996) 331-335.

[8] N. Wanderka, M.-P. Macht, M. Seidel, S. Mechler, K. Stahl, J.Z. Jiang, APL 77 (2000) 3935-3937.

[9] S. Mechler, PhD Thesis, Technical University of Berlin, Germany (2007).
[10] S. Mechler, N. Wanderka, M.-P. Macht, Int. J. Mater. Res. 101 (2010) 601-610.

[11] J.H. Perepezko, R.J. Hebert, R.I. Wu, Mater. Sci. Forum 386-388 (2002) 11-20.

[12] J.-J. Kim, Y. Choi, S. Suresh, A.S. Argon, Science 295 (2002) 654-657.

[13] N. Boucharat, R. Hebert, H. Rösner, R. Valiev, G. Wilde, Scripta Mater. 53 (2005) $823-827$.

[14] Zs Kovács, P. Henits, A.P. Zhilyaev, A. Révész, Scripta Mater. 54 (2006) 1733-1737.

[15] J.-M. Liu, A. Wiedenmann, U. Gerold, U. Keiderling, H. Wollenberger, J. Phys. Condens. Matter 9 (1997) 2731-2738.

[16] S. Schneider, P. Thiyagarajan, W.L. Johnson, APL 68 (1996) 493-495.

[17] E. Pekarskaya, J.F. Löffler, W.L. Johnson, Acta Mater. 51 (2003) 4045-4057.

[18] A.V. Feoktystov, H. Frielinghaus, Z. Di, S. Jaksch, V. Pipich, M.-S. Appavou, E. Babcock, R. Hanslik, R. Engels, G. Kemmerling, H. Kleines, A. Ioffe, D. Richter, T. Brückel, J. Appl. Cryst. 48 (2015) 61-70.

[19] E.W. Fischer, A. Bakai, A. Patkowski, W. Steffen, L. Reinhardt, J. Non-Cryst. Solids 307-310 (2002) 584-601.

[20] Heinz Maier-Leibnitz Zentrum, et al., KWS-3: J. Large-Scale Res. Facil. 1 (2015) A31.

[21] Yu. Petrusenko, A. Bakai, I. Neklyudov, S. Bakai, V. Borysenko, G. Wang, P.K. Liaw, T. Zhang, J. Alloy. Comp. 5095 (2011), 5123-5123.

[22] I. Breßler, J. Kohlbrecher, A.F. Thünemann, J. Appl. Cryst. 48 (2015) 1587-2159. 